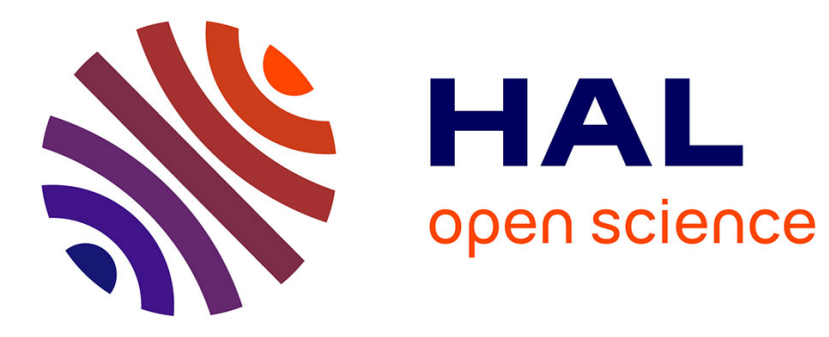

\title{
Applying Design Thinking for Prototyping a Game Controller
}

\author{
Gabriel Ferreira Alves, Emerson Vitor Souza, Daniela Gorski Trevisan, \\ Anselmo Antunes Montenegro, Luciana Cardoso de Castro Salgado, Esteban \\ Walter Gonzalez Clua
}

\section{To cite this version:}

Gabriel Ferreira Alves, Emerson Vitor Souza, Daniela Gorski Trevisan, Anselmo Antunes Montenegro, Luciana Cardoso de Castro Salgado, et al.. Applying Design Thinking for Prototyping a Game Controller. 17th International Conference on Entertainment Computing (ICEC), Sep 2018, Poznan, Poland. pp.16-27, 10.1007/978-3-319-99426-0_2 . hal-02128631

\section{HAL Id: hal-02128631 \\ https://hal.inria.fr/hal-02128631}

Submitted on 14 May 2019

HAL is a multi-disciplinary open access archive for the deposit and dissemination of scientific research documents, whether they are published or not. The documents may come from teaching and research institutions in France or abroad, or from public or private research centers.
L'archive ouverte pluridisciplinaire HAL, est destinée au dépôt et à la diffusion de documents scientifiques de niveau recherche, publiés ou non, émanant des établissements d'enseignement et de recherche français ou étrangers, des laboratoires publics ou privés. 


\title{
Applying Design Thinking for prototyping a game controller
}

\author{
Gabriel Ferreira Alves, Emerson Vitor Souza, Daniela Gorski Trevisan, \\ Anselmo Antunes Montenegro, Luciana Cardoso de Castro Salgado, and \\ Esteban Walter Gonzalez Clua \\ Universidade Federal Fluminense, Instituto de Computacao, Niteroi RJ 24210-310, \\ Brazil. gabrielferreiraalves@id.uff.br, esouza@id.uff.br, \\ daniela@ic.uff.br, anselmo@ic.uff.br, luciana@ic.uff.br, \\ esteban@ic.uff.br
}

\begin{abstract}
Game controllers design is undergoing a major shift due to the disruptive forces of new paradigms of interaction and a wide set of game genres. With so many approaches involving this device, in this work we want to address the challenge of generating ideas for a totally new and innovative game controller that pleases its players. In order to achieve this objective, we applied a set of Design Thinking techiques such as one day in life, empathy map, persona, ideation workshop, paper prototyping and experimental tests. The results have shown that the techniques were useful in informing and guiding idea generation and were perceived as appealing. Drawing on observations and participants feedbacks, we reflect on the strengths of using this methodology to develop games controllers and discuss some of the needs that they still have.
\end{abstract}

Keywords: Gamepad · Design Thinking $\cdot$ games $\cdot$ controllers.

\section{Introduction}

Digital games have become a major technological force, given the evolution in computational power employed in it. Such area has exceeded the limits of entertainment and have become educational, simulation and even sports tools. Many innovations have been proposed for new game interfaces, mostly focused in gesture and body movement interpretation and motion based sensors, such as accelerometers and gyroscopes [15]. However, the paradigm of the traditional gamepad has proved to be irreplaceable, with most console games still relying on it.

With all this evolution going on in digital gaming environments, gameplay controllers also go through evolution, though not as drastic: controllers, also known as joysticks or gamepads, have undergone some changes over the years, receiving more buttons, features, components and devices. Thanks to its dynamics (like touchscreen, Wi-Fi/Bluetooth connection, sensors, etc), smartphones have become universal controllers. Among the various types, video game controls are included. Although they have the potential to control games due to the various 
components present in their hardware and software, smartphones have a major disadvantage: the lack of tactile feedback. Due to the lack of physical buttons where the user can feel a return of the action being performed, the number of times he needs to look at the screen is greater than when a joystick is used, which can directly result in his performance during a game [1].

This work seeks to use a design technique that allows generating a great amount of ideas in a short period, making designers to immerse themselves in the proposed subject and thus develop solutions to the problem. Therefore, we chose Design Thinking as method because it meets these requirements and it allows to understand user needs and understand their principle problems in daily life [8]. Based on studies and researches on the various types of controllers for video games in the market and in the literature [1][9][2][16], this work seeks, through applying Design Thinking techniques, to discover the strengths and weaknesses of existent controllers and propose one or more controllers that can be used by lovers of digital games, casual gamers and even people who do not play at all.

This paper is organized in four sections, including the introduction. In Section 2 we present the works that relate to this. In Section 3 we describe the methodology and results. Finally, in Section 4, we conclude, summarizing our contributions and sharing new research questions and future work.

\section{Related Work}

When searching for images using the word "joysticks", you can find various game controllers with different formats, sizes, number of buttons and connection systems with devices that are controlled. These devices began their career by being just a little box with a button and a lever, then getting added action buttons, directional buttons, until they have wireless connections, motion sensors, and tactile screens [2]. Nintendo's latest innovative invention relies on cardboard and user creativity to build its controllers, called the Nintendo Labo for Nintendo Switch [12].

Some solutions for virtual controllers have been developed to help the player deal with the lack of tactile feedback, as can be seen in Figure 1. Companies have developed controllers that communicate with smartphones via Wi-Fi or USB connections so that the player is able to perform action on games for mobile devices with greater excellence.

In his work, Baldauf et al. [1] did a comparative laboratory study where four gamepad designs were developed using a framework created by the authors for touchscreen smartphones, which are equivalent of existing controllers and have been tested in two popular games: the arcade game Pac-Man and the platform game Super Mario Bros. This comparative study was done seeking to make evident what the main characteristics that users would realize that physical and virtual controls have different and in common with each other.

After the application of tests with users, several participants related the gamepad with the respective physical controllers and mentioned the negative lack of tactile feedback. The post-test comments included that the buttons were 


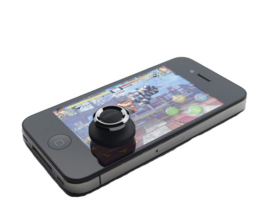

1

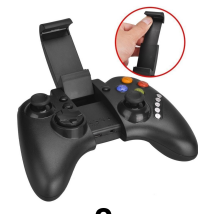

2

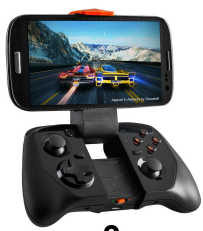

3

Fig. 1: Some models of mobile controllers: 1) Grayhaus Brick Joystick[3]; 2) Ipega 9021[7]; 3) Moga Hero Power[10].

difficult to reach precisely, that the especially opposite directions were difficult to press, and thus, the looks at the device were necessary. This is the main point raised in surveys that consider the use of virtual controls. On the other hand, it was said that the control that had movement sensor and device rotation can be interesting in games that require the player to perform such movement, as in racing games, for example.

Meanwhile, Merdenyan et al. [9] review the gamepads of four video games (Logitech Gamepad F310, Microsoft Xbox 360 Controller for Windows, DualShock 4 Wireless Controller for PlayStation 4 and Wii Classic Controller Pro) by users to investigate which improvements are required in their designs. The content was taken from user ratings posted on 'Amazon.com' through December 15, 2014. The sampling policy for reviews was: twenty comments for each of the four gamepads were sampled using Amazon.com's "Most Helpful First" review criteria and only the 50-500 word evaluations were sampled. The collected data revealed that the main characteristics raised on the controllers were: battery life, comfort, compatibility, durability, ease of use, functionality, layout (button positioning), quality of the material, recognition, responsiveness and user manual.

Through research carried out in academic search libraries such as Google Scholar and the ACM library, we sought to find design thechniques focused on solutions for game controllers interaction. Although we could find works using Design Thinking techniques in the area of Game Design [6][4], there were no studies related to the use of Design Thinking process applied to the design of game controllers. In this direction our work describes the experience obtained and the lessons learned in using the Design Thinking process to create a unique game controller.

\section{Design Thinking Application and Results}

In order to find out a game controller solution that is capable to fit all kind of games interaction and still pleases its players, a study was conducted using Design Thinking as a methodology. The Design Thinking refers to the designer's way of thinking, which uses abductive thinking. In this type of thinking, it is sought to formulate questions through the apprehension or understanding of the phenomena, that is, questions are formulated to be answered from the 
information collected during the observation of the universe that permeates the problem [14].

Over the years, several models and pipeline proposals of Design Thinking have emerged, where each one seeks to better suit the profile and the research environment. To perform this work we used the model proposed by the Stanford d.school [14], chosen for its level of detail of processes and ease of understanding. The pipeline proposed by d.school consists of a few steps, where each step is composed of one or more techniques. Figure 2 shows the pipeline used in the design of the gaming controller. It is important to say that though we have presented this pipeline as a sequence of activities, this is not mandatory and the activities can be combined according to each project needs.

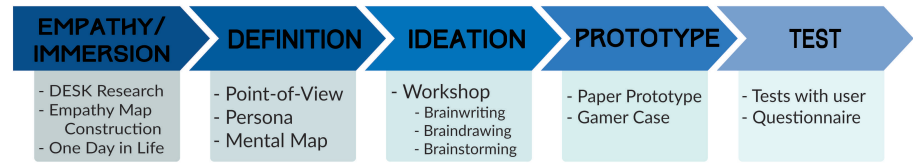

Fig. 2: The pipeline used in the design of the gaming controller.

\subsection{Empathy and Immersion}

The first step is called "Empathy and Immersion". At this point the project team approaches the context of the problem, both from the point of view of the designer and the end user. In order to empathize with the subject and immerse it in it, three techniques of this first stage of Design Thinking process were used: the DESK Research, where it is sought to find general knowledge about the subject matter; the Empathy Map, an artifact constructed with the purpose of knowing better the aspects related to the interaction between the user and the research environment; and the "One Day in Life", which consists of living a day in the skin of the player, seeking to understand their feelings and thoughts.

When performing the DESK Research, mainly using the material described in the related work section, some relevant data were collected. Joysticks are important tools in the world of virtual games, responsible for giving the player control of actions within games. It is this tool that integrates and separates, at the same time, the player from the virtual world. The first joysticks consisted of two boxes with two switches (for rotation and acceleration) and a firing button. Over time, the controllers have grown and evolved, gaining directional buttons, motion sensors, touchscreen contact areas and several other features [2].

After that, we considered an Empathy Map workshop with stakeholders (researchers engineers, designers, gamers and non gamers participants). Empathy maps focus on identifying what other people are thinking, feeling, doing, seeing, and hearing as they engage with a product or service. Findings obtained when creating the map are found in Figure 3. However, while we felt like this tool was 
helpful in isolating their interaction with a product, we thought it lacked the context of real-life or real observation on the activity of playing. Because of this, the second technique, called One Day In Life, was applied.

\begin{tabular}{|c|c|c|}
\hline \multicolumn{3}{|c|}{ PLAYERS } \\
\hline Positive points: & What do users hear about it? & Negative points: \\
\hline $\begin{array}{l}\text { Have weight control; } \\
\cdot \text { Have tactile screens; } \\
\cdot \text { Have standardization } \\
\text { (within the same company). }\end{array}$ & $\begin{array}{l}\text { "The control is of quality"; } \\
\text { ""There are controls for } \\
\text { professional players"; } \\
\text { •"X control is better } \\
\text { than Y control." }\end{array}$ & $\begin{array}{l}\text { They do not have accessibility } \\
\text { - High costs; } \\
\text { - Low durability; } \\
\text { - Amount of buttons } \\
\text { - (many buttons can scare); } \\
\text { Lack of standardization } \\
\text { between controls. }\end{array}$ \\
\hline What do users feel? & What do users say about it? & What do users see about it? \\
\hline $\begin{array}{l}\text { Envy of other controls; } \\
\text { Happiness when using } \\
\text { a new control; } \\
\text { Comfort / Discomfort; } \\
\text { Difficulty / ease when } \\
\text { using a control; } \\
\text { Good quality/poor } \\
\text { quality. }\end{array}$ & $\begin{array}{l}\text { "X control is better than } \\
\text { Y control"; } \\
\text { "The control is of quality"; } \\
\text { "I like playing with } \\
\text { this control." }\end{array}$ & $\begin{array}{l}\text { Friends playing; } \\
\text { - YouTubers playing; } \\
\text { - Number of buttons; } \\
\text { - Aesthetics of control; } \\
\text { - Professional players } \\
\text { playing. }\end{array}$ \\
\hline
\end{tabular}

Fig. 3: Empathy Map.

Seeking to immerse in the lives of players using multiple controllers, four models of joysticks were used to control games: Nintendo 3DS controller, Steam controller, DualShock 4 for PlayStation 4 and Xbox One controller. Some random games were played, like Portal 2, Pokemon X and Super Mario Bros using the controllers that can be seen in Figure 4.

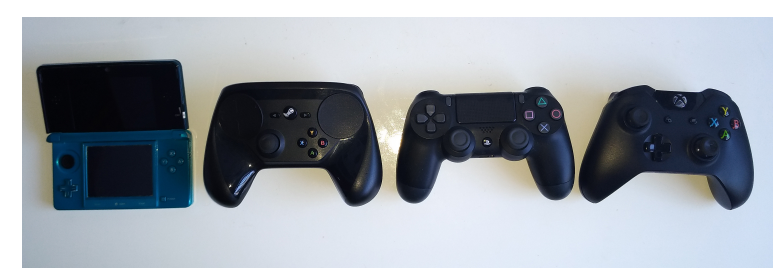

Fig. 4: Game controllers observed. From left to right: Nintendo 3DS, Steam, PlayStation 4 and Xbox One.

Given the variation between the number of functionalities, the layout of buttons, shape and size of the controller, some evaluations were carried out. Two of the researchers owned video games. Seeking a way to make the search valid, gamers have played games with controllers they are unfamiliar with. Researcher 1 (R1) owns a Nintendo 3DS, while Researcher 2 (R2) owns a PlayStation 4. Thus, R1 used the Steam, Xbox One and PlayStation 4 controllers to play, while R2 used the Steam, Xbox One and Nintendo 3DS controllers. A volunteer (V1), who owns the Steam and XboX One controllers, also participated in the research, 
running games using the Nintendo 3DS and PlayStation 4 controllers. After being tested with all controllers, the researchers and the volunteer responded to a questionnaire which was assessed using the Likert 7-point scale.

The following aspects were analyzed:

Q1: Did you feel comfortable using the controller?

Q2: Did you find the button layout pleasant?

Q3: Did you find the size of the buttons reasonable?

Q4: Would you use this controller regularly while playing?

Q5: Did you find that the controller is ergonomic?

The results can be found in the table below.

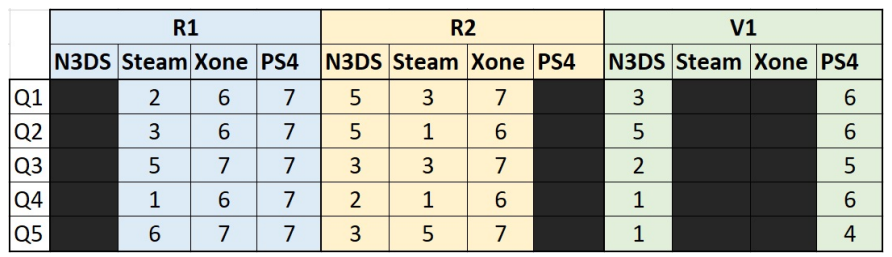

Fig. 5: One Day in Life results.

Each controller received a note from two different evaluators who did not have contact with that type of controller previously, avoiding the introduction of bias in the evaluation. The Nintendo 3DS and Steam controllers achieved lower scores when compared to the Xbox One and PlayStation 4 controllers: on ergonomic issues, button size, and hence comfort, the Nintendo 3DS is rated with low scores. The Steam controller achieved a good ergonomics rating but was unable to please players over the good response in-game. The Xbox One and PlayStation 4 controllers had high ratings and almost all the requirements, pleasing the evaluators.

\subsection{Definition}

The second stage of Design Thinking is called Definition. It consists of synthesizing the findings of the empathy process into compelling needs and insights. It is a mode of focus rather than flaring. The purpose of the definition is to develop a deep understanding of users and the design space and, based on this understanding, present a statement of the problem - the Point of View (PoV). The Point of View defined for our research was created following the findings in the Empathy and Immersion stage, and consists of the following sentence: "A player needs good controller because he seeks to achieve good performance, overcome obstacles in games, achieve goals and feel comfortable while playing with his/her friends".

With the PoV in mind, together with the insights gained from the Empathy and Imersion techniques, a Persona was defined so that it became possible to 
study in more detail the needs of the player. This persona-player had experience in several different platforms of video games, being they PlayStation 4, Xbox One, Nintendo DS and Computer. More details can be found in Figure 6.

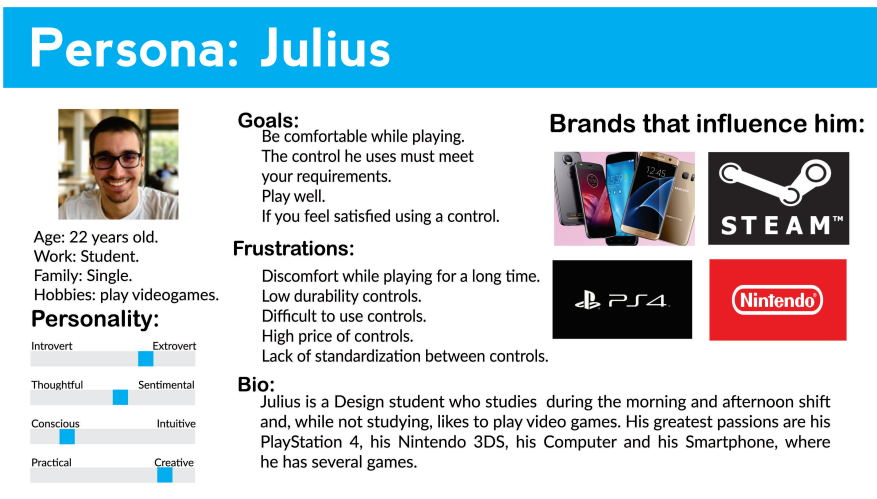

Fig. 6: The persona developed in the definition phase.

In addition to the persona, a Conceptual Map (the Mental Map) was also defined, in which the characteristics related to the research environment were listed. The Conceptual Map is a graphical view, built to simplify and visually organize data at different levels of depth and abstraction. Its purpose is to illustrate the links between the data and produce new meanings that are extracted from the information raised in the initial stages of the Immersion phase. It can be found in Figure 7.

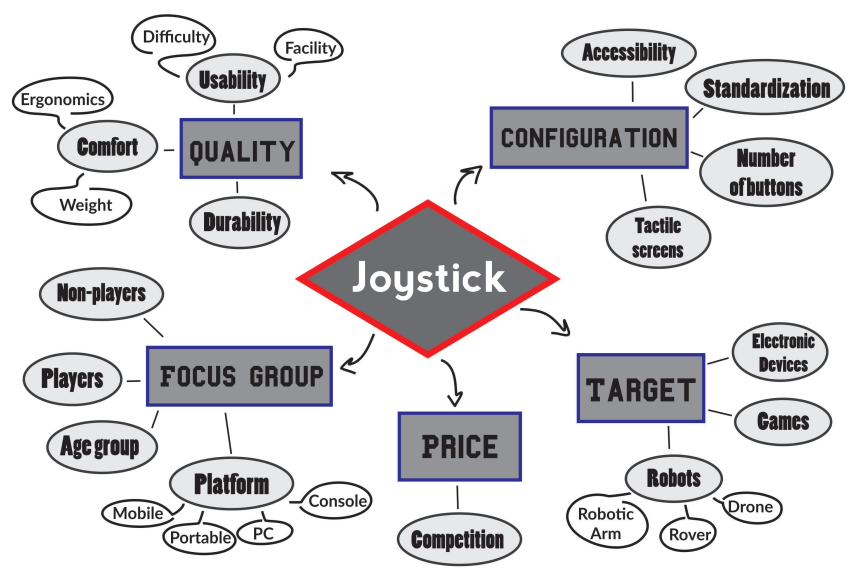

Fig. 7: The mental map used in the definition phase. 


\subsection{Ideation Workshop}

After all the constructions in the topic of Definition, we move on to the next step of Design Thinking: Ideation. At this stage a workshop was developed with engineers researches, designers, players and non players partipants. This workshop was a way to make all participants feel more integrated with the subject and also to state their opinions and develop solutions in creative ways.

At the beginning of the Workshop participants were presented with what was the subject of the research and what was the purpose of that activity. The Point of View developed in the Definition stage along with the Persona that they should be basing to develop the desired solution were presented. Both are important to make participants assiduous of the research theme. Next, some existing game scenarios were presented. These scenarios allowed participants to know that the controllers developed by them should work perfectly in all types of games, such as action games, adventure games, sports games and other.

To begin the practical part of the Workshop, participants were grouped into two groups. There were eight participants, among them, six men and two women, with ages between 20 and 30 years. Of the participants, only two did not have contact with digital games.

The first activity developed was Brainwriting [13]. Brainwriting is a variation of Brainstorming that allows a group to be able to generate a lot of ideas in a short period of time. In this activity only one sheet of paper, pencil and eraser is used, and the participants' creativity is stimulated. For this activity, each of the groups with four members of each group was responsible for writing, on a blank sheet, the requirements that they believed a controller must possess in order to be able to perform all the necessary activities within a game. After two minutes of thinking and writing a requirement, the members switched the sheets clockwise. Each member of the group who received a sheet from his colleague had to examine the requirement that the colleague had written, comment below whether or not he agreed with him and why, and then add another requirement to the paper. After completing the cycle, the Brainwriting stage was completed and the group was able to discuss the results written on each sheet.

The next step was Braindrawing [13]. Braindrawing is also a variation of Brainstorming, where participants had to draw what they believed a video game controller should possess. As in Brainwriting, the members of each group had a limited time to design components of a video game controller, and after the time ended, the participant at their side had the task of supplementing the controller that he started. At the end of the cycle, a totally new controller was generated.

After the Braindrawing, each group met to discuss the results of their texts and drawings, pick up pertinent points, and perform a Brainstorming. The idea here was for each group to unite their findings and generate a single result that encompasses all or a large part of the results they found during Branwriting and Braindrawing. After Brainstorming, the groups presented the results to the rest of the classmates: each one exemplified his solution to the problem, where a controller could adapt to the varied contexts of the games. Figure 8 shows their solutions. 

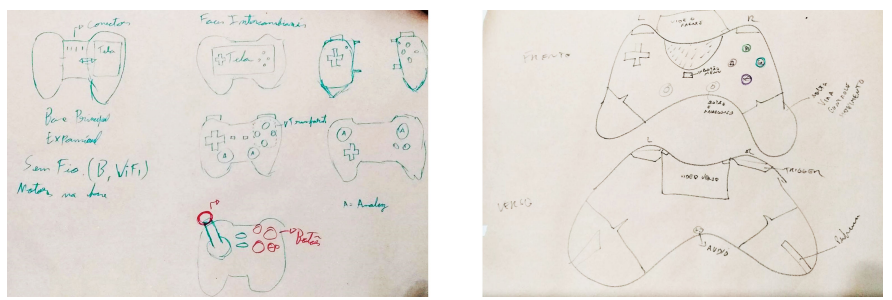

Fig. 8: Group 1 and Group 2 solutions.

\subsection{Prototyping}

Based on the results generated in the Workshop, we analyzed and selected interesting components of each idea generated. It was possible to notice that participants prefer physical controllers to virtual ones, given the lack of tactile feedback from the second, but the participants were tempted to integrate both controller models to form a single component. The first one was called "Modular Controller", which makes it possible to create your own physical controller while a smartphone runs a virtual controller application. The second solution was named "Gamer Case". Both of them are shown in Figure 9.

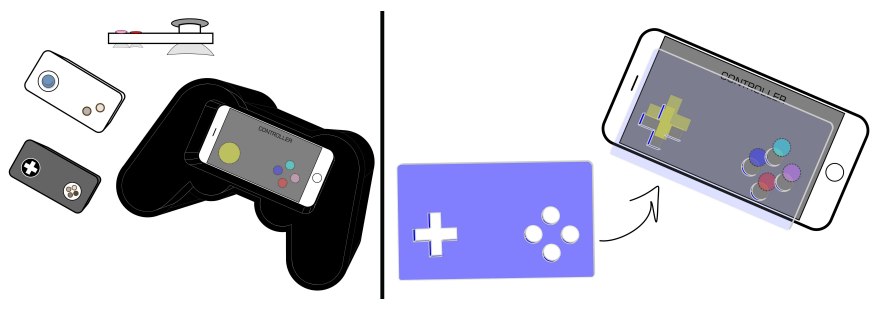

Fig. 9: The "Modular Controller" and the "Gamer Case".

The Modular Controller is summarized in a physical base of joystick as already known, but empty. In its central region there is a space where you can deposit your smartphone, running software that simulates a gamepad virtually. The innovation of this controller comes in modules that can be plugged into your controller, which can be developed into a three-dimensional modeling software and printed on a 3D printer, fully functional for the controller you need to use. This module has buttons with suction cups that, when they fit in the space that contains the smartphone, touch the screen of the device and perform the actions that it should do individually. This solution is versatile, since you can assemble your own controller and also solves the problem of the lack of tactile feedback that the virtual controller has. It is important to note that the joystick casing does not work separate from the smartphone: it is only a support for the phone, being the true game controller. 
The solution that the Gamer Case provides is to try to solve the lack of tactile feedback that digital controls have, as mentioned in Baldauf et al. [1], that is, the user can not realize that he is actually pressing a button on the virtual control. Thus, using a 3D printer, for instance, it is possible to print punched transparent films with the format that suits the virtual controller software (cross, d-pad, buttons, etc.) and place it on top of the device, leaving only exposed areas which must be clicked by the player (see Figure 10). In this way, the user can feel if he is actually touching the correct area of the controller, increasing his performance when performing the actions within the game.

\subsection{Experimental tests}

In the testing phase, as follows the Design Thinking pipeline chosen by d.school, the Gamer Case solution was implemented so that some informal tests could be performed. Before starting the tests, participants were given a User Profile questionnaire to fill out. At the end of this questionnaire the tests were started.

For the experiment, 12 people with age group between 18 and 60 years of age participated. Among them, 67\% were male and $33 \%$ were female, 11 had smartphones for more than 2 years and $42 \%$ of the participants have a habit of playing. To perform the tests was used a smartphone Zenfone 3 Zoom with 4 GB of RAM and 64 GB of internal storage. In it was run a software that simulates a virtual controller called PC Remote [11], which connects via Wi-Fi with a computer that, in turn, runs the game. Players could choose between playing Sonic The Hedgehog (Master System) or Super Mario Bros (NES). Figure 10 shows both the virtual controller and the Gamer Case.

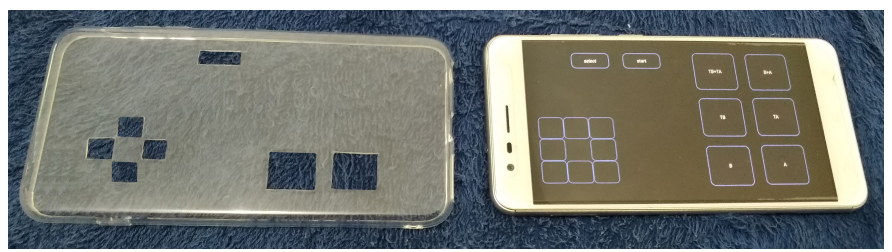

Fig. 10: The Gamer Case and the virtual gamepad.

In the first phase of the tests, the player was responsible for playing, for five minutes, the game of his preference using the smartphone without the Gamer Case. In the second phase, the Case was placed on the smartphone and it resumed the game for another five minutes. After completing the tests, an informal questionnaire was made available so that users could evaluate the two ways to use the controller. Figure 11 shows two users playing Super Mario Bros using the controller with and without the Gamer Case solution.

Given the participants' responses about controller without the Gamer Case, $83 \%$ stated that they felt uncomfortable using it, $58 \%$ stated that the controller 

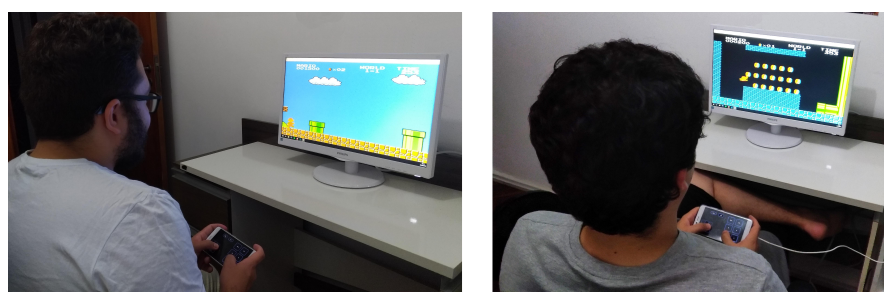

Fig. 11: Player using the virtual gamepad without (left) and with (right) the Gamer Case.

is user-friendly but could be better, and only $8.3 \%$ gave a grade 4 (on a scale of 1 to 5 , where 1 is too bad and 5 is too good) for the controller, $33.3 \%$ gave a grade $3,50 \%$ gave a grade 2 and $8.3 \%$ gave a grade 1 . Meanwhile, when using the controller with the Gamer Case, $58.3 \%$ felt very comfortable using it, $91.7 \%$ managed to perform the tasks properly and $50 \%$ evaluated it with the maximum score.

\section{Final Considerations}

The main contributions of this work are the use of the Design Thinking methodology for the development of new ideas and solutions for game controllers that can help the player to have a better experience when playing.

Existing controllers have great similarities but also diverge on some points that can leave the user a little confused when using them after getting used to another. Virtual controllers, despite using innovative technologies such as the gyroscope and the accelerometer, have one major disadvantage: the lack of tactile feedback. With this work, as already observed in previous works [5][16] we realized that the participants prefer a physical controller to a virtual one. However they did not fail to integrate the two solutions.

By using the techniques of Design Thinking, it was possible for a group of people to develop a solution that would unite both the physical and virtual approaches that a video game controller can have. All the steps: Empathy and Immersion, Definition, Ideation Workshop and Prototyping were followed seeking to develop an interesting and innovative result. Based on this, the Modular Controller - a modular physical controller that can be integrated and built with the help of mobile devices and customizable modules - and the Gamer Case a case for smartphones that suits the screen leaving only touchable where the user has to touch - were created, making the experience that the player can have something totally new.

By understanding how to design innovative game controllers, the Design Thinking techniques used in this process shown to be efficients to alternate between moments of focusing and spreading ideas. Therefore, with this study we find in the techniques of Design Thinking support to develop two innovative solutions in a short period of time and in a simple and inexpensive way. 


\section{References}

1. Baldauf, M., Fröhlich, P., Adegeye, F., Suette, S.: Investigating on-screen gamepad designs for smartphone-controlled video games. ACM Transactions on Multimedia Computing, Communications, and Applications (TOMM) 12(1s), 22 (2015)

2. Cornish, D.: History of the video game controller. Available in: (https://www.shortlist.com/tech/gaming/history-of-the-video-gamecontroller/3231). Accessed on April 26, 2018; 4:15 pm. (2018)

3. DesignBoom: Grayhaus brick joystick. Available in: (https://www.designboom.com/readers/grayhaus-brick/). Accessed on April 27, 2018; 1:17 pm. (2018)

4. Games, I.A., Squire, K.: Design thinking in gamestar mechanic: The role of gamer experience on the appropriation of the discourse practices of game designers. In: Proceedings of the 8th international conference on International conference for the learning sciences-Volume 1. pp. 257-264. International Society of the Learning Sciences (2008)

5. Gonçalves, G., Mourão, É., Torok, L., Trevisan, D., Clua, E., Montenegro, A.: Understanding user experience with game controllers: A case study with an adaptive smart controller and a traditional gamepad. In: International Conference on Entertainment Computing. pp. 59-71. Springer (2017)

6. Hayes, E.R., Games, I.A.: Making computer games and design thinking: A review of current software and strategies. Games and Culture 3(3-4), 309-332 (2008)

7. Ipega: Pg-9021. Available in: (http://www.ipega.hk/). Accessed on April 27, 2018; 1:17 pm. (2018)

8. Lugmayr, A., Stockleben, B., Zou, Y., Anzenhofer, S., Jalonen, M.: Applying design thinking in the context of media management education. Multimedia Tools and Applications 71(1), 119-157 (2014)

9. Merdenyan, B., Petrie, H.: User reviews of gamepad controllers: A source of user requirements and user experience. In: Proceedings of the 2015 Annual Symposium on Computer-Human Interaction in Play. pp. 643-648. ACM (2015)

10. Moga: Moga hero power. Available in: (http://www.mogaanywhere.com/controllers/ heropower). Accessed on April 27, 2018; 1:17 pm. (2018)

11. Monect: Pc remote. Available in: (https://www.monect.com/pc-remote/). Accessed on May 02, 2018; 2:05 pm. (2018)

12. Nintendo: Nintendo labo for the nintendo switch. Available in: (https://labo.nintendo.com/). Accessed on April 26, 2018; 3:54 pm. (2018)

13. Paulus, P.B., Brown, V.R.: Enhancing ideational creativity in groups. Group creativity: Innovation through collaboration pp. 110-136 (2003)

14. Plattner, H.: Bootcamp bootleg. Design School Stanford, Palo Alto (2010)

15. Tara, R.Y., Teng, W.C.: A suitability evaluation of controlling 3d map viewpoint by gamepad orientation for remote navigation. IEEE Access 5, 10686-10693 (2017)

16. Torok, L., Pelegrino, M., Trevisan, D., Montenegro, A., Clua, E.: Smart controller: Introducing a dynamic interface adapted to the gameplay. Entertainment Computing 27, 32-46 (2018) 